\title{
Problems and Countermeasures of Bike-sharing Tourism in China Zheng-Ke YANG ${ }^{1, a}$, Kai-Ling DONG ${ }^{2, b}$, Xue-Mei ZHANG ${ }^{1, c, *}$ \\ ${ }^{1}$ College of Tourism, Economy and Management, Chengdu University, China \\ ${ }^{2}$ College of Rail Transportation, Chengdu Vocational \& Technical College of Industry, China accolinyoung@126.com, b283927050@qq.com, c276863381@qq.com
}

Keywords: Bike-sharing tourism, Problems, Countermeasuers, China.

\begin{abstract}
Bike-sharing has developed rapidly in China, it's not only convenient for the citizens but it also has quietly infiltrated into the tourism market at the same time. It has gradually become a new and fashionable way of travelling. In this paper, the authers analyzed the characteristics of bike-sharing tourism and discussed the problems and countermeasures of bike-sharing tourism.
\end{abstract}

\section{Introduction}

Bike-sharing is widely welcomed and has been fond of by the citizens as it solves the traffic problem known as the "Last Mile" in and around the city center by a low-carbon, environmental and healthy way. As a result, the number of the bike-sharing users is increasing rapidly. And what's more, as a new and fashionable way of travelling, it's becoming popular riding this kind of bike to travel around the city or the scenic spot. Bike-sharing is developing rapidly in China, and what are the characteristics of bike-sharing tourism? What are the problems of developing bike-sharing tourism in China and how to solve these problems have been discussed in the paper.

\section{Research Method}

With the methods of field investigation and literature analysis, the characteristics and problems of bike-sharing tourism in China are analyzed, and the countermeasures of developing bike-sharing tourism are also discussed.

\section{Conception and Characteristics of Bike-sharing Tourism}

\section{The Conception of Bike-sharing Tourism}

The essence of bike-sharing tourism is bicycle tourism. Bicycle tourism refers to the tourism way of riding for a single day or many days from one place to another ones, and the main purpose of bicycle tourism is based on leisure, entertainment and vacation. From the perspective of sports tourism, bicycle tourism includes the related contents of both sports and tourism, so it's a branch of sports tourism. According to the length of time, distance, number of people, ways and purpose of riding, bike-sharing tourism could be divided into the following different types.

For example, according to length of time, it can be divided into a single day tour or a multi day tour and so on. According to the distance, it can be divided into long-distance travel and travel around. According to the number of people, it can be divided into a single person tour and a group tour. According to the way of cycling, there are simple cycling and riding with other means of transportation. According to the purpose of riding, there are leisure tours and fitness tours and so on.

The main purposes of having a bike-sharing tourism are seeking for leisure time,having entertainment,spending vacations and physical exercise.There for,the main characteristics of bike-sharing tourism can be concluded as follows.At first,the riding distance is short and the intensity of riding is low.On the second,bike-sharing tourism provides alternative ways of travel.And for the most important,the tourists in a bike-sharing tour will have different travelling experience from a self-driving tour or a group tour. 


\section{The Characteristics of Bike-sharing Tourism}

\section{Strengthen the Capacity of the Traffic}

Though there are well-run metro and bus transportation systems in most first-tier cities,the inconvenience from the bus station or the metro station to the destination is still a problem which known as the "last mile"tough problem. The convenient and flexible operation mode of bike-sharing complements the existing public traffic system,and as a result,a"point to point"transport service appeared.

This kind of service meets the needs of the citizens on short trip and improves the capacity of the traffic. The reason why bike-sharing system has a positive significance in alleviateing the urban traffic congestion, such as it saving time for citizens and improving the efficiency of traffic system, it is that the sharing bikes are smaller than cars, so they're easy to get across the streets and pass through the traffic jam quickly.

\section{An Environment-friendly Way of Travel}

Traffic jam,air pollution and haze weather have become common problems in cities,and one of most important reasons is the increasing number of vehicles in urban.According to the data from Delgado Corporation,travelling by bike instead of by car can reduce 200 grams of $\mathrm{CO}_{2}$ emission per kilometre. Although this amount is not very eye-catching,if the number of users who use the bike-sharing system is large,it's function to protect the environment will be much more significant.

The bike-sharing system can not only meets the needs of short trip from the citizens,but also it's helpful to solve problems such as traffic jam and urban environment pollution From this point of view,the bike-sharing system corresponds to the idea of green,low carbon and environment protection, and it provides a new way of travelling for tourists.

\section{No Using Limitation}

Although the essence of bike-sharing tourism is bicycle tourism,there are still differences between them.As the 'sharing'characteristic of the bike-sharing,participants in the bike-sharing tourism don't have to prepare for bikes and other equipments.And also,they don't need worry about where to park the bike and whether the bike might be stolen as the sharing bike is everywhere.The participants in the bike-sharing tourism can choose to ride a sharing bike and take other transports for different periods during a tour,when and where to go will be limitless.

There're different ways to combine the sharing bike with other transports.For example,tourists can choose to take public transport to the scenic areas first,and then ride a sharing bike to finish the sightseeing.They can also ride the sharing bike for a distance and then take other transports for a period,and at last they can go home by the sharing bike or by public transports. Therefore,tourists will have a more convenient,more relaxing and more comfortable tour as they can determine or arrange travelling time,travelling route and ways of travelling according to their preferences or feelings.

\section{Rich in Experience Personally}

It brings bike-sharing tourism more advantages than traditional tourism as the characteristics such as slow travelling and flexible choices.Bike-sharing tourism can make tourists get close to the city more deeply and bike-sharing tourists will turn sightseeing into experiential tourism.Tourists will have rich travelling experience because they can visit the city from different angles and find the beauty or differences of it according to their own preferences.

\section{Existing Problems of Bike-sharing Tourism in China}

\section{The Vacancy of Government Management Functions}

Though the bike-sharing programs are provided by private enterprise and not free,to a certain extent they are public service.The bike-sharing as a transport has a great impact on people's travel and the traffic situation,and the government should concentrate on the management of the access permission and regulate the operations. 
For example,the standards that a bike-sharing company should acquire before launching sharing bikes to the city and the public parking areas should be formulated early. The guarantee of the service,the possible risks and measures also should be appraised.

\section{Confusion in Parking and Management}

For their own convenience,most users park the bikes at wrong areas and this kind of bad habit has encouraged some unwelcome behaviors.Because of the confusion in parking,pavements are blocked and traffic chaos happened.

In addition,some selfish people hide the sharing bikes in their own homes or office buildings incase that when they wanna ride,they can find a bike easily. What's more,in certain areas or at certain time it's difficult to find even one bike but it's surprising to find hundreds of bikes in another area,and the disorder of bike dispatching and throwing in will contribute to this phenomenon.

\section{The Deposit is not Easy to Withdraw}

Different from the traditional lease deposit,the lease deposit of the bike-sharing program isn't one-to-one relationship but one-to-many.It means one sharing bike will be paid deposit by different users for many times.As a result,the deposit has some financial functions which will cause risks and social problems.

\section{There are Potential Risks of Bike-sharing Tourism}

There are no quality or safe standards for the sharing bikes,and the damage rate of bikes is relatively high.Figures showed that even in mo-bike,a bike-sharing operating company which claims possess the lowest damage rate in the industry,the damage rate is close to $10 \%$ actually. This means that if there is no timely maintenance,it may lead to certain security risks.And in addition,potential safety hazard may exist because of the heavy traffic,concentration lackness and disobeying rules during the riding.

\section{Infrastructures in Rural Areas are Backward}

At present,the greenways in rural areas around the city is not perfect and the construction plan of the parking location for sharing bikes in scenic area are not reasonable.In the countryside,some traffic signs,such as the bicycle lanes, are not clear.So the essential infrastructure conditions to develop the bike-sharing tourism in rural areas are still need to be improved.

\section{Countermeasures to the Existing Problems of Bike-sharing Tourism in China}

\section{Consummate Systems and Normative Management}

The authorities should make relevant laws or regulations to improve the behaviors of both bike-sharing operating companies and users. The law must be obeyed by users and anyone who breaks the law must be punished.

In order to standardize and restrict the bad behaviors of the enterprises or users and promote the orderly development of the bike-sharing industry, the bike-sharing riding credit system should be set up. Governmental department, such as police or transportation, should manage the credit system according to the law, and punish the illegal enterprises or users according to the relevant regulations.

\section{Improve Public Facilities and Create Tonditions for Bike-sharing Tourism}

To create perfect infrastructure conditions for bike-sharing tourism,the construction of greenways in cities and surrounding rural areas should be well finished,and reasonable plans for parking lots and bicycle lanes in scenic areas or spots for sharing bikes should be made.

\section{Strengthen the Supervision of the Deposit}

Although the amount of single deposit is a little,there are millions of users and the total amout of deposit is extremely large. Because the deposit is not subject to supervision,many companies, except for the company that ran away with the money,use the deposit for enterprise operation. 
Through preliminarily combed,media discovered that 6 bike-sharing operating companies were closed and the loss of users' deposit exceeded about 1 billion RMB according to rough statistics. Therefore,the deposit charged by bike-sharing operating companies should be kept in the third party custody account and subject to supervision,and can't be misappropriated without authorization in order to protect the interests of the vast number of users.

\section{Investigate the Potential Safety Hazard and Optimize Management}

In order to eliminate the tial safety hazard of the sharing bikes,operating companies must pay more attention to ensure the quality of bikes and check the bikes regularly in various ways.

To provide users with security guarantee,operating companies should maintain the broken bikes timely and purchase the corresponding insurance for the bikes. To optimize management,the big data technology can be introduced to the scientific management of sharing bikes. For example,according to the proportion of the regional population,we can allocate bicycles scientifically,plan parking areas reasonably and deploy bicycles quickly according to the use of bicycles at different time periods.

\section{Protect the Ecological Environment to Achieve Sustainable Development}

The blue sky, white clouds,green hills and green water are the most important issues for tourists. A good ecological environment is the basis of rural tourism. It is necessary to handle the relationship between the utilization of resources and the protection of the ecological environment correctly,and establish the idea of “lucid waters and lush mountains are invaluable assets"firmly.

Being in line with scientific attitude and method,we should develop and utilize tourism resources in an orderly way,so as to truly achieve a win-win situation of tourism economic development and ecological environment improvement.

\section{Summary}

To start with,bike-sharing has been widely popularized in various cities in China for its convenience,environment protection,fitness and other advantages,and it has also been widely recognized by the public.Furthermore,bike-sharing has corresponded to the ideas of leisure,fitness and environment protection, and promoted the development of leisure tourism in urban and surrounding areas.Last but not least,bike-sharing has become a booster for the development of urban tourism and rural tourism as a new way,and has injected new vitality into the development of sharing economy.

\section{Acknowledgements}

This research was one of the achievements in a major program of Sichuan Leisure Sports Industry Development Research Center(NO:XXTYCY2017A02).And the research was also supported by a program from Sichuan Provincial Department ——Tourism Economic Management and Exhibition Innovation Team(NO:16TD0037).

\section{References}

[1] Ping ZHU, Ya-Cheng ZHU, Kun WANG, The value, dilemma and outlet of the development of bike-sharing in China, China Collective Economy.26(2017)1-2. (In Chinese)

[2] Jia MI, Yi-Ming CHEN, The Development Status and Strategy of Bike-sharing, Journal of Lanzhou Insitute. 10(2017)65-67. (In Chinese)

[3] Jing-Le ZHANG, Development status and trend of bike-sharig in sharing economy, Chinese, Foreign Entrepreneurs,23(2017)108-109. (In Chinese)

[4] Hong-Yao LIANG, Ling YAO, the Development Situation and Countermeasure of Sharing Economy in the View of “Internet+”,China Marcket Marcketing,27(2017)56-59. (In Chinese) 
[5] Xiao-Yi ZHAO, Xi-Yu FAN, The development strategy of bike-sharing from the closing of WuKong bike, China Circulation Economy,9(2017)75-78. (In Chinese)

[6] Zi-Xuan ZHANG, Wei WU, The current situation, problems and suggestions for development of bike-sharing, Modern Business,5(2017)162-163. (In Chinese)

[7] Jie YANG, Development of urban public bicycle rental system in China,Journal of Shanxi University of Finance and Economics,S1(2017)63-64. (In Chinese)

[8] Yan-Xia LIU, Problems in bicycle riding tour and suggestions for improvement,Journal of Tianjin Trade Union Administrators’ College,3(2014)63-64. (In Chinese)

[9] Yu-Zi PAN. Analysis of bike-sharing market,Co-Operative Economy \& Science, 10(2017)76-77. (In Chinese)

[10] Xiao-Jun ZHAO, Research on the development of bike-sharing industry based on the mobile internet,Contemporary Economics,11(2017)10-11. (In Chinese)

[11] Yu-Jing LU, Analysis of bike-sharing profit model based on O2O Perspective,Marketing Management Review,7(2017)36-37. (In Chinese)

[12]Qi-Yan ZHANG,An analysis of the legal rules and regulations of bike-sharing,Legal and Economy,7(2017)99-100. (In Chinese)

[13]Xiao-Ling ZHANG,Shi-Shu LIU YANG,Legal dilemma and development countermeasures of bike-sharing,Legal and Economy,8(2017)73-74. (In Chinese)

[14]Xiao-Wang SI,Analysis of the legal problems in bike-sharing,Hebei Enterprise,9(2017)151-152. (In Chinese)

[15] Ya-Jun WAN, Meng RUI, Bicycle tourism - the exploration and practice of bicycle application, China Bicycle,6(2008)42-45. (In Chinese)

[16]Bi-Hu WU,Zhuo-Wei HUANG,Xiao-Meng MA, Spatial Structure of Rural Tourism Attractions in Suburban Areas of China, Scientia Geographica Sinica,12(2004)757-762.(In Chinese) 